\title{
Sistema Educativo para o Ensino dos Algoritmos de Transporte
}

\author{
Priscyla Cristhina dos Santos Alessandra Martins Coelho \\ IF Sudeste MG câmpus Rio Pomba, Av. Dr. José Sebastião da Paixão s/nº. \\ Bairro Lindo Vale - Rio Pomba / MG - CEP: 36180-000 \\ e-mail: santos_priscyla@hotmail.com \\ e-mail: alessandra.coelho@ifsudestemg.edu.br
}

\begin{abstract}
RESUMO
Impulsionados pelo avanço da tecnologia, os métodos utilizados para o ensino vêm sofrendo modificações tanto na transferência do conhecimento para o aluno, quanto na absorção desse conhecimento por ele. A grande questão que envolve esse processo de ensino-aprendizagem é fazer com que a informação seja adquirida de forma perceptível, independente do método proposto [5].

É descrito em [2] que a Pesquisa Operacional (PO) consiste em utilizar métodos científicos, como modelos matemáticos, estatísticos e algoritmos computacionais para a tomada de decisões. Muitas vezes esses métodos são difíceis de ser compreendidos pelos alunos, necessitando que o professor aprimore mais seu método de ensino [4]. Em aulas de PO é natural o apoio ao uso de softwares como LINDO, CPLEX e GPPSS ARENA para a resolução dos problemas. No entanto, eles não possuem a característica de agregar conhecimento ao aluno, devido ao fato de não apresentarem nenhuma informação de como chegar à solução [5], ou seja, é possível solucionar problemas sem o conhecimento das técnicas de $\mathrm{PO}$, o que é desinteressante para o processo de ensino-aprendizagem.

Programas com foco didático que apresentam suas iterações de maneira autoexplicativa podem contribuir tanto para o professor durante o ensino, quanto para alunos durante o aprendizado [4]. Esforços nesse sentido também podem ser vistos em [1], que descreve um trabalho desenvolvido na disciplina de PO, resultando em softwares tutoriais para solucionar Problemas de Programação Linear via Simplex. Do mesmo modo, a ideia deste trabalho surgiu após a implementação desenvolvida na disciplina de PO, cujo objetivo foi solucionar Problemas de Programação em Redes (PPR), via Algoritmos de Transporte.

A representação de um PPR é feita utilizando os conceitos de grafos bipartidos. Devido à facilidade de visualização e compreensão de suas características, o modelo de Redes vem sendo empregado em áreas de negócio, como transporte e finanças [2]. Na Tabela 1 estão apresentados os problemas fundamentais que envolvem a PPR e os principais algoritmos para a sua solução.
\end{abstract}

\begin{tabular}{ll}
\hline \multicolumn{1}{c}{ Problema } & \multicolumn{1}{c}{ Solução Principal } \\
\hline Clássico de Transporte & Algoritmo de Transporte \\
Transbordo & Algoritmo de Transporte \\
Designação de Tarefas & Método Húngaro \\
Caminho mais Curto & Algoritmo de Dijkstra \\
Fluxo Máximo & Algoritmo de Ford-Fulkerson \\
Árvore Geradora Mínima & Algoritmo de Prim e Kruskal \\
\hline
\end{tabular}

Tabela 1 - Principais Problemas de Programação em Redes.

Visando tornar as aulas de PO mais atrativas, de maneira que o aluno não apenas aplique os softwares, mas entenda o comportamento do algoritmo usado, esta pesquisa visa o desenvolvimento de um sistema educativo para o ensino dos Algoritmos de Transporte (SEEAT) via Web, cujo objetivo é apresentar, além do resultado final, a representação gráfica, passo-apasso, de como solucionar o problema proposto. Dessa maneira, a solução gráfica estará relacionada com os dados do problema inserido, mudando a sua representação a cada novo problema.

O sistema está sendo desenvolvido na linguagem PHP, devido a facilidade de ser escrito 
no meio de uma página HTML, tornando mais fácil a geração de páginas web dinâmico [3]. Também foi utilizada a biblioteca GD que compilada ao PHP possibilitou gerar as imagens relacionadas aos grafos.

A Figura 1 exemplifica uma solução inicial do problema inserido. Foram realizados os seguintes passos: (1) inserção dos dados do problema e escolha do método gerador da solução inicial (Canto Noroeste, Custo Mínimo ou Aproximação de Vogel); (2) apresentação na forma tabular do problema. No caso de oferta e demanda serem diferentes, uma nova matriz é gerada com a inclusão da origem/destino fantasma; (3) a cada iteração do algoritmo é mostrado o que realmente acontece através das matrizes, até chegar à solução básica factível (SBF) inicial.

Ao final da execução do algoritmo, o usuário tem a opção de visualizar, também, toda a modelagem do problema através de um grafo. Para cada iteração do algoritmo, um novo grafo é apresentado e uma explicação é inserida, mostrando assim, a quantidade retirada de uma Origem $i$ e inserida no Destino $j$. Na figura 1(c) é possível ver o grafo gerado com as mesmas informações da figura 1(a) continuando em 1(b) .

(a)
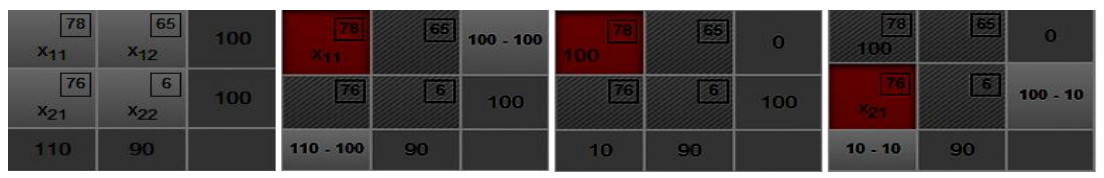

(b)
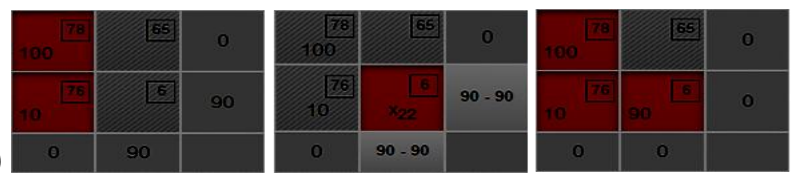

(c)
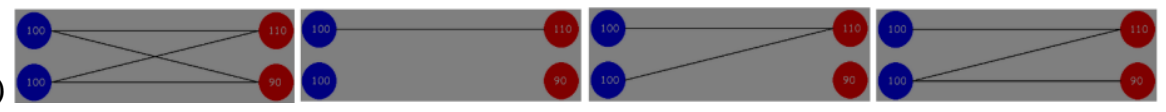

Figura 1 - Exemplo de uma Solução Inicial pelo Método do Canto Noroeste

Como o sistema encontra-se em fase de implementação, as explicações referentes a cada iteração do problema ainda não estão apresentadas na tela. Os testes serão realizados com alunos que já tenham cursado e que estiverem cursando a disciplina de PO, para verificar a utilidade durante o estudo dos algoritmos de transporte. Comprovada sua utilidade, outros algoritmos serão implementados, com a mesma proposta deste trabalho.

Palavras-chave: Programação em Redes, Software Educativo, Algoritmo de Transporte

Agradecimento: Os autores agradecem à FAPEMIG e ao IF SUDESTE MG pelo apoio.

\section{Referências}

[1] G. de F. Aguiar, Concepção e Teste de Software no Processo de Ensino-Aprendizagem da Disciplina Pesquisa Operacional, em "XL Congresso Brasileiro de Educação em Engenharia", 2012.

[2] P. Belfiore, "Pesquisa Operacional para Cursos de Engenharia", ELSEVIER, Rio de Janeiro, 2013.

[3] J. Hackenhaar, Um comparativo entre PHP e JSP: definindo a melhor aplicação para o desenvolvimento de projetos web, Revista iTEC, vol. 1, pp 32-36, ( 2010).

[4] J. A.G. de A. Júnior, Desenvolvimento de um Software Didático para o Ensino de Programação Linear, em "VIII SEPRENE", 2012.

[5] R. Veras, E-PL: Um objeto de Aprendizagem para o Ensino de Programação Linear, em "VIII Simpósio Brasileiro de Sistemas de Informação", pp.743 - 754, 2012. 